


\title{
OPEN Self-healing polysaccharide-based hydrogels as injectable carriers for neural stem cells
}

Received: 22 August 2016

Accepted: 27 October 2016

Published: 29 November 2016

\author{
Zhao Wei ${ }^{1, *}$, Jingyi Zhao ${ }^{2, *}$, Yong Mei Chen ${ }^{1}$, Pengbo Zhang ${ }^{2}$ \& Qiqing Zhang ${ }^{3}$
}

Self-healing injectable hydrogels can be formulated as three-dimensional carriers for the treatment of neurological diseases with desirable advantages, such as avoiding the potential risks of cell loss during injection, protecting cells from the shearing force of injection. However, the demands for biocompatible self-healing injectable hydrogels to meet above requirements and to promote the differentiation of neural stem cells (NSCs) into neurons remain a challenge. Herein, we developed a biocompatible selfhealing polysaccharide-based hydrogel system as a novel injectable carrier for the delivery of NSCs. $\mathrm{N}$-carboxyethyl chitosan (CEC) and oxidized sodium alginate (OSA) are the main backbones of the hydrogel networks, denoted as CEC-I-OSA hydrogel ("I" means "linked-by"). Owing to the dynamic imine cross-links formed by a Schiff reaction between amino groups on CEC and aldehyde groups on OSA, the hydrogel possesses the ability to self-heal into a integrity after being injected from needles under physiological conditions. The CEC-I-OSA hydrogel in which the stiffness mimicking nature brain tissues $(100 \sim 1000 \mathrm{~Pa}$ ) can be finely tuned to support the proliferation and neuronal differentiation of NSCs. The multi-functional, injectable, and self-healing CEC-I-OSA hydrogels hold great promises for NSC transplantation and further treatment of neurological diseases.

Transplantation of neural stem cells (NSCs) is a promising therapeutic strategy for the treatment of neurological diseases ${ }^{1-3}$. Transplanted NSCs are expected to proliferate and differentiate in the lesion cavity, and eventually integrate with the host tissue to promote neural regeneration. Biomaterial-based cell delivery systems which loaded NSCs within biocompatible and biodegradable soft materials, are explored as an important strategy for increasing cell population, promoting differentiation and prolonging cell function in $v i v o^{4-7}$.

Soft and biocompatible hydrogel, possessing three-dimensional (3D) polymer networks and physicochemical properties similar to the extracellular matrices of tissues ${ }^{8-11}$, can provide the $3 \mathrm{D}$ microenvironment for the differentiation and engraftment of transplanted NSCs. Injectable hydrogel, delivering cells into localized lesion site within any defect shape via minimally invasive manner, has been extensively applied in the delivery of NSCs ${ }^{12-14}$. In the case of conventional injectable hydrogels used for the transplantation of NSCs, both the cell suspension of floating cells and hydrogel precursors are injected into the target site simultaneously, then the cells are embedded into the polymer networks of the hydrogels after gelation. Unfortunately, the conventional injectable hydrogels without self-healing ability may be easily damaged by external forces which further seriously deteriorate their functionalities. Therefore, self-healing hydrogels, which can automatically restore their integrity of network structures and functionalities after damages without the need of external interventions, have been explored to meet the needs of biomedical applications ${ }^{15-18}$. Currently, the self-healing injectable hydrogels, possessing the dual capabilities of self-healing and injection, are emerging as a new generation of multifunctional vehicles for cell therapy ${ }^{19-21}$. Different from the conventional injectable hydrogels, self-healing injectable hydrogels can directly deliver cells via transplanting the cell-loaded hydrogel fragments which can self-heal into integral connected structures after filling a lesion site. 
Self-healing and injectable hydrogels can provide several advantages over the conventional injectable hydrogels in cell delivery ${ }^{22,23}$, including: (i) avoiding the potential risks of cell loss during the injection, as well as providing necessary mechanical protections for the delivered cells from the shear damage during the injection ${ }^{24,25}$; (ii) confirming the morphologies and functionalities of the cells loaded inside the 3D microenvironment to control the quality of the loaded cells before transplantations; (iii) facilitating the fast mechanical recovery of the damaged hydrogels, keeping intrinsic functionalities and expanding the service life of implanted cell-loaded hydrogels ${ }^{26-28}$.

So far, few self-healing hydrogels have been developed as injectable carriers for cell delivery. For example, Ma et al. presented a self-healing dextran-based hydrogel consisted of multiple-hydrogen-bond units (ureido-pyrimidinone, Upy) modified dextran chains, which can achieve rapid self-integration through the hydrogen bond between Upy units ${ }^{29}$. Two pieces of self-healed cell-loaded hydrogels which separately loaded with chondrocytes and bone marrow stem cells can form cartilage-bone tissue complex after subcutaneous implantation. Liu and coauthors synthesized self-healing injectable hydrogel via dynamic imine bonds between multiple aldehyde groups on chondroitin sulfate and N-succinyl-chitosan. The HeLa cells encapsulated into the hydrogel remain viable and metabolically active ${ }^{30}$. However, achieving the self-healing and injectable capabilities for NSC delivery in the treatment of neurological lesions still remains sparse. To this end, self-healing injectable hydrogels should possess the biomechanical property similar to that of native brain tissues, and should also provide a suitable microenvironment for the proliferation and neuronal differentiation of NSCs.

To address the emerging need for self-healing injectable hydrogels with improved functionality for the delivery of NSCs, we had developed a polysaccharide-based self-healing injectable hydrogel system mimicking the biomechanical properties of brain tissues. The polysaccharide networks of the self-healing injectable hydrogels, denoted as CEC-1-OSA hydrogel ("l" means "linked-by"), are cross-linked by the reversible imine bonds formed from a Schiff base reaction of the amino groups on N-carboxyethyl chitosan (CEC) and the aldehyde groups on oxidized sodium alginate (OSA). The chitosan and sodium alginate are chosen as the backbones of the polymer networks due to cytocompatibility, water solubility, low-cost, and abundant in nature ${ }^{31}$. Especially, the amino groups on chitosan promote nerve regeneration ${ }^{32-35}$. The imine bonds via Schiff reaction are attributed to the family of dynamic covalent bonds which can establish an intrinsic dynamic equilibrium of bond association and dissociation in hydrogel networks, offering self-healing capability to the CEC-l-OSA hydrogels. The self-healing injectable CEC-1-OSA hydrogels with the stiffness similar to nature brain tissues $(100 \sim 1000 \mathrm{~Pa})^{36,37} \mathrm{can}$ be formed in situ via dynamic imine bonds, through facilely mixing the solution of CEC and OSA under physiological environment. Moreover, the NSCs loaded inside the self-healing injectable hydrogels maintain the normal functions of proliferation and differentiation, hold promises for the transplantation of NSCs and the treatment of neurological diseases.

\section{Results and Discussion}

The transplantation strategy of NSCs loaded CEC-1-OSA hydrogel is shown in Fig. 1. Briefly, cell-loaded CEC-l-OSA hydrogels were prepared in advance before the injection. Firstly, CEC and OSA were dissolved into DMEM-12 (DF-12) culture medium separately, and the NSCs were suspended in the OSA component. After mixing the CEC component and the OSA component with cells, NSC-loaded CEC-l-OSA hydrogels can be obtained via Schiff base reactions. To provide a microenvironment with mechanical properties to match that of brain tissues, as well as facilitating NSC proliferation and differentiation, the shear modulus of CEC-1-OSA hydrogels was adjusted to the order of 100 1000 Pa. The NSC-loaded CEC-1-OSA hydrogels exhibited excellent self-healing and injectable properties under physiological conditions. The cell loaded hydrogels were squeezed through a syringe to fill the lesion cavity. Subsequently, the cell-loaded fragments of hydrogel could self-heal into a whole at the target site, which would fill up the irregular shapes of lesion cavities. The detailed information of CEC-l-OSA hydrogel preparation, self-healing behaviors, mechanical properties, as well as proliferation and differentiation of NSCs inside the CEC-l-OSA hydrogels will be discussed here.

Preparation of CEC-I-OSA hydrogel. Chitosan was modified with acrylic acid through Michael's reaction to enhance its water solubility under physiological conditions, and the sodium alginate was periodate-oxidized to OSA with aldehyde groups ${ }^{19}$. The synthesis of CEC and OSA are well established, simple and green. It is an organic-solvent-free reaction and only water is used in the processes of modification. Moreover, the only byproduct of the dynamic Schiff crosslinking reaction is water and the cytotoxicity of the hydorgel is minimal. (Supplementary Fig. S1). In order to meet the actual demand of cell cultivation and transplantation, the CEC-1-OSA hydrogels were prepared in DF-12 medium of NSCs under physiological conditions. The CEC-1-OSA hydrogels can be facilely prepared in situ by mixing CEC DF-12 solution and OSA DF-12 solution via Schiff base reaction. The polysaccharide chains are cross-linked by dynamic imine bonds among the reactive groups modified on the polymer chains, i.e., amino groups on CEC and the aldehyde groups on OSA. A series of CEC-l-OSA hydrogels were obtained by mixing the OSA solution of a fixed concentration $\left(C_{\mathrm{o}}=0.1 \mathrm{~g} / \mathrm{mL}\right)$ with different concentration of the CEC solution $\left(C_{\mathrm{c}}=0.01 \sim 0.03 \mathrm{~g} / \mathrm{mL}\right)$. The molar ratio of the reactive groups was kept at $1\left(\mathrm{M}-\mathrm{NH}_{2}: \mathrm{M}-\mathrm{CHO}=1\right)$ to ensure the theoretically complete cross-linking of the amino groups and aldehyde groups in two components.

The vial inversion method was used to determine gelation times of the CEC-1-OSA hydrogels with various CEC concentrations $\left(C_{c}\right)$. At $37^{\circ} \mathrm{C}$, the flowability of the CEC and OSA mixtures dramatically decreased with mixing time. The CEC-1-OSA hydrogels were formed via the dynamic covalent imine cross-links. The gelation time of the CEC-1-OSA hydrogels was dependent on CEC concentration, which took the longest time of $71.5 \pm 3.5 \mathrm{~min}$ for the lowest $C_{\mathrm{c}}$ of $0.01 \mathrm{~g} / \mathrm{mL}$. When gradually increasing the $C_{\mathrm{c}}$ from 0.01 to $0.03 \mathrm{~g} / \mathrm{mL}$ at intervals of $0.005 \mathrm{~g} / \mathrm{mL}$, the gelation was accelerated and the gelling time sharply decreased to $35.8 \pm 3.6,24.4 \pm 2.9$, $3.4 \pm 0.3$ and $2.4 \pm 0.2 \mathrm{~min}$ for $C_{\mathrm{c}}=0.015,0.02,0.025$ and $0.03 \mathrm{~g} / \mathrm{mL}$, respectively (Fig. $2 \mathrm{a}$ ). These results indicate that the higher the concentration of CEC and the reactive groups of amino and aldehyde in the networks, the 




Figure 1. The transplantation strategy of injectable NSC-loaded, self-healing CEC-1-OSA hydrogels. CEC and OSA are dissolved into DF-12 medium, respectively, and the NSCs are suspended in the OSA medium. After mixing the DF-12 medium containing CEC and the cell suspension containing OSA, NSC-loaded CECl-OSA hydrogels can be obtained via Schiff base reaction. Subsequently, the needle of the syringe is inserted into a lesion cavity, and the cell-loaded hydrogel fragments will be injected into the lesion cavity for NSCs transplantation. (The drawings of the rat, the hand and the two syringes in the figure are obtained from the clip art library of ChemBioDraw Ultra 12.0).
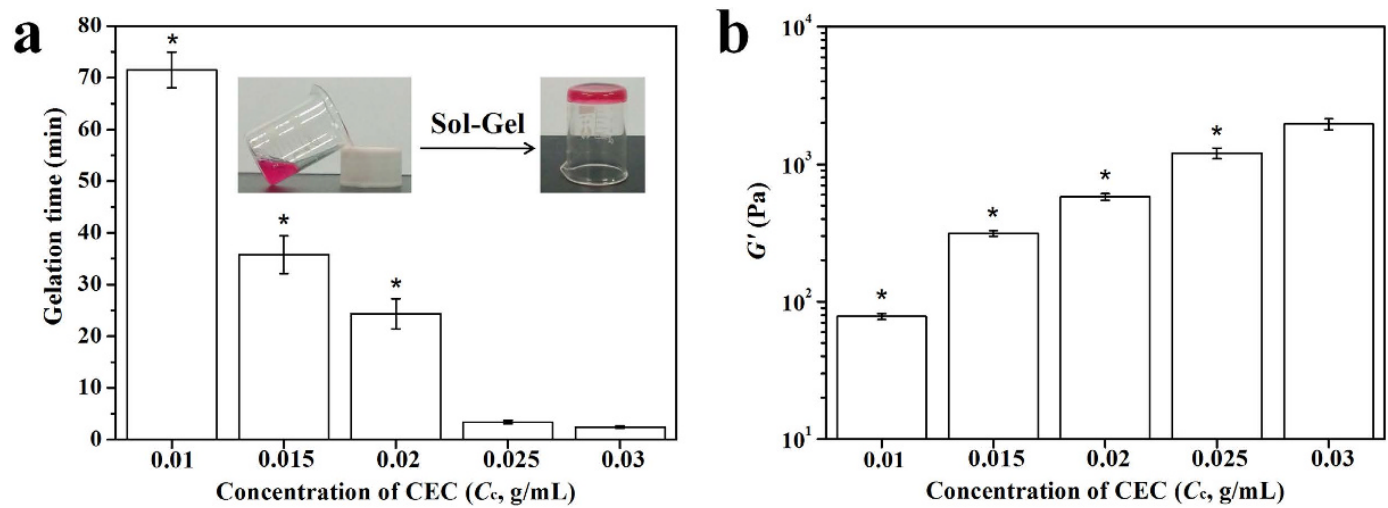

Figure 2. The gelation time and storage moduli $\left(G^{\prime}\right)$ of the CEC-1-OSA hydrogels with various CEC solutions $\left(C_{\mathrm{c}}=\mathbf{0 . 0 1} \sim \mathbf{0 . 0 3} \mathrm{g} / \mathrm{mL}\right)$ under physiological conditions. (a) The gelation time of the CEC-1-OSA hydrogels. (b) The $G^{\prime}$ of the CEC-l-OSA hydrogels. The data are extracted from the plateaus of variation of $G^{\prime}$ versus angular frequency $(1$ to $10 \mathrm{rad} / \mathrm{s})$. ${ }^{\star}$ Symbol indicated the significant differences $(\mathrm{p}<0.05)$ between samples with $\mathrm{C}_{\mathrm{c}}=0.03 \mathrm{~g} / \mathrm{mL}$ and samples at other CEC concentrations. Error bars represent standard deviations $(n=3)$.

faster gelation of the hydrogel. Whereas, for the samples with low CEC concentrations $\left(C_{\mathrm{c}}<0.01 \mathrm{~g} / \mathrm{mL}\right)$, hydrogel formation was not observed, indicating that as the concentrations of the polymers and reactants are too low to meet the minimum requirements for gelation. On the other hand, the samples with $C_{c}>0.03 \mathrm{~g} / \mathrm{mL}$ failed to form homogeneous hydrogels due to the high viscosities of the polymer solutions preventing homogenous mixing.

To study the effect of CEC concentration on the mechanical properties of the CEC-l-OSA hydrogels, we performed the rheological test of the hydrogels with various $C_{\mathrm{c}}$ (Fig. 2b). The storage modulus $\left(G^{\prime}\right)$ rose from $77.9 \pm 3.9 \mathrm{~Pa}$ to $1961 \pm 178 \mathrm{~Pa}$ when $C_{\mathrm{c}}$ was increased from 0.01 to $0.03 \mathrm{~g} / \mathrm{mL}$. The higher concentrations of 


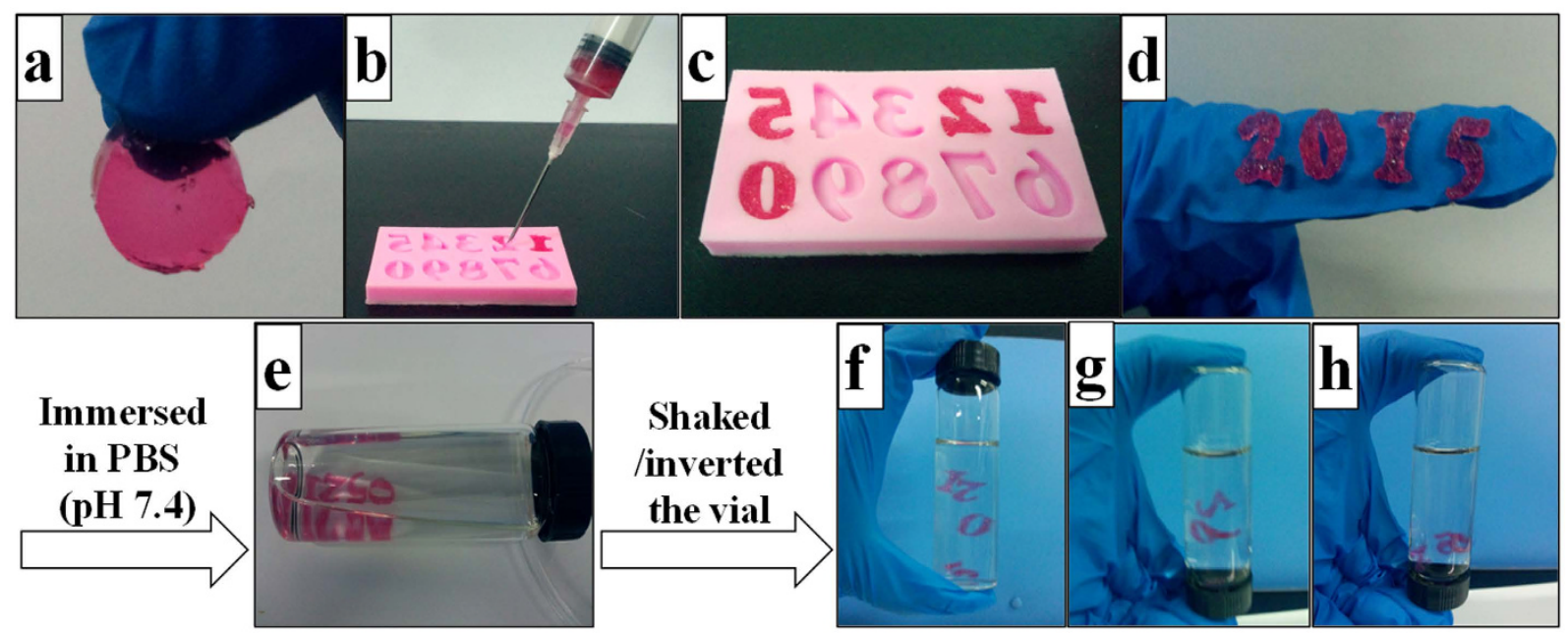

Figure 3. The injectable performance and self-healing capability of one CEC-1-OSA hydrogel $\left(C_{\mathrm{c}}=0.02 \mathrm{~g} / \mathrm{mL}\right)$. (a) A disc-shaped hydrogel is formed after mixing CEC and OSA. (b) Gelled material was loaded into a syringe and squeezed out into the " 2 ", " 0 ", " 1 ", " 5 " spots in a number mold. (c) The gel fragments were self-healed into continuous " 2015 " structures after 5 minute-culture at $37^{\circ} \mathrm{C}$ without any external intervention. (d-h) The self-healed structures were stable in PBS ( $\mathrm{pH} 7.4$ ) under shaking and inverting motions.

reactive groups as well as the increased amount of CEC, contribute to a significant increase in storage modulus. It is well-known that the $G^{\prime}$ of normal neural tissues are in the range of $10^{2} \sim 10^{3} \mathrm{~Pa}^{38,39}$, which can be fully covered with the adjustable $G^{\prime}$ of CEC-1-OSA hydrogels through controlling the concentration of CEC. This indicates that the CEC-l-OSA hydrogels can be potentially used as biomaterials for neural tissue engineering.

The CEC-1-OSA hydrogels are degradable through hydrolysis. The degradation behaviors of the CEC-l-OSA hydrogels with the various concentrations of CEC were investigated in DF- 12 medium under $37^{\circ} \mathrm{C}$ (Supplementary Fig. S4), The hydrogels swelled in the DF-12 medium in the first few days, and then degraded by 3 to 14 days along with the $C_{c}$ varying from 0.01 to $0.03 \mathrm{~g} / \mathrm{mL}$. Besides the hydrolysis, the polypeptides (such as growth factors and serum with amino groups) contained in the DF-12 medium may also contribute to the degradation of the polymer networks.

Self-healing behavior and mechanical recovery of the injectable CEC-I-OSA hydrogel. Considering the dynamic imine cross-links existed in the hydrogel networks and the low storage modulus, the CEC-l-OSA hydrogels can be injected from syringes through needles into the lesion sites. The hydrogels possess the self-healing ability after injection. To test the injectability and self-healing ability, CEC-l-OSA hydrogels with CEC concentration at $0.02 \mathrm{~g} / \mathrm{mL}$ and $G^{\prime}$ at $577 \pm 31 \mathrm{~Pa}$ were tested as a model hydrogel. A hydrogel disc was put into a 21 -gauge syringe and extruded through a needle into number molds with the shape of " 2 ", " 0 ", " 1 ", " 5 " (Fig. 3a,b). The number molds filled hydrogel fragments were left at $37^{\circ} \mathrm{C}$ for $5 \mathrm{~min}$ without any external interventions, the hydrogel fragments self-healed via dynamic imine bonds and turned into dense hydrogels with the shape of the numbers (Fig. 3c). The hydrogels in number shapes were stable when exposed to gentle shaking and inverting of the vials filled with phosphate buffered saline (PBS) $(\mathrm{pH}=7.4)$ (Fig. 3d-h). These tests demonstrated good injectability and the excellent self-healing capability of the CEC-l-OSA hydrogels when exposed to the physiological saline.

To assess the mechanical properties of the self-healing CEC-l-OSA hydrogels after injection, we performed the rheological measurements of the samples prepared in DF- 12 culture medium $\left(C_{c}=0.02 \mathrm{~g} / \mathrm{mL}\right)$ under 3 different conditions (Supplementary Fig. S5). One was a self-healing samples, i.e., injecting disk-shaped hydrogels into a circular mold via a syringe with a needle, then the fragments of the hydrogels were set aside for 5 min (denoted as $H_{S}$ ). The second sets were samples of freshly gelled, i.e., directly mixing CEC DF-12 solution and OSA DF- 12 solution into a circular mold. After gelation for 25 minutes, the samples were set for 5 more minutes before the rheological test (denoted as $H_{T}$ ). The third sets of samples (control) were prepared at the same condition as the sample set \# 2, but set aside for $24 \mathrm{~h}$ before the rheological test (denoted as $H_{\mathrm{C}}$ ). When sweeping with time, the $G^{\prime}$ of the $H_{\mathrm{S}}$ samples immediately reached up to $365 \mathrm{~Pa}$ at initial time, which is close to that of the $H_{\mathrm{C}}$ sample $(577 \mathrm{~Pa})$. However, at start time, the $G^{\prime}$ of the $H_{\mathrm{T}}$ sample was as low as $12 \mathrm{~Pa}$ which is $30-48$ times lower than that of the $H_{\mathrm{S}}$ and $H_{\mathrm{C}}$ samples. Moreover, the $G^{\prime}$ slowly rose with sweeping time and only reached $59 \mathrm{~Pa}$ after $1600 \mathrm{~s}$ (Fig. 4a). It indicates that the mechanical modulus of the CEC-1-OSA hydrogels can be built up more quickly by adopting the self-healing injection manner. Whereas, seriously delaying in the increment of the storage modulus over a long period of time is exhibited when the sample is freshly prepared from two components as in conventional injection with two-syringe based mixing at the time of injection. CEC-1-OSA hydrogels may have a potential risk of hydrogel displacement and cell loss during the injection when using conventional mixing approach during the transplantation. The results indicate that the injectable self-healing CEC-l-OSA hydrogels support fast 

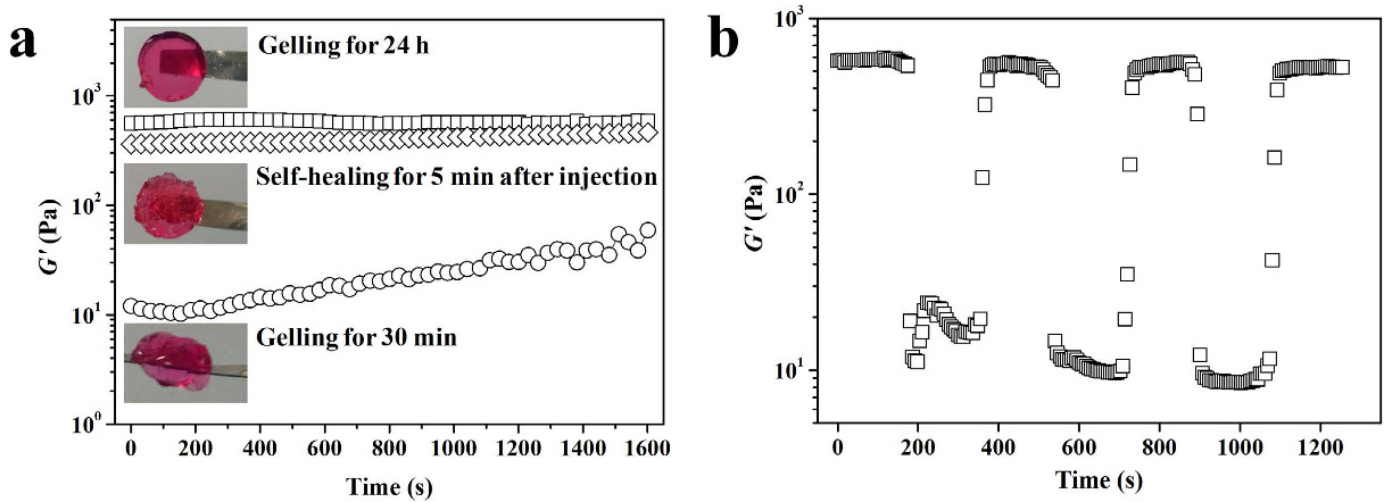

Figure 4. The rheological measurement of self-healing CEC-1-OSA hydrogel. (a) The $G^{\prime}$ of the CEC-1-OSA hydrogels after setting for $24 \mathrm{~h}(\square)$ and $30 \mathrm{~min}(\diamond)$, as well as self-healing for $5 \mathrm{~min}$ after injection through a needle (O). (b) The $G^{\prime}$ of the CEC-l-OSA hydrogel from alternate step strain sweep with small strain $(\gamma=0.1 \%)$ for $100 \mathrm{~s}$ and following large strain $(\gamma=1000 \%)$ for $200 \mathrm{~s}$ at a fixed angular frequency $(10 \mathrm{rad} / \mathrm{s})$ at $37^{\circ} \mathrm{C}$.

mechanical recovery, facilitate to keep intrinsic functionalities, guard against cargo loss, as well as expand the service life of injected hydrogels.

To further confirm the self-healing behaviors of the CEC-1-OSA hydrogel after injection, the continuous step-strain measurements were conducted to test the rheological recovery behaviors of the $H_{\mathrm{S}}$ hydrogels (Fig. 4b). Briefly, the oscillatory shear strain of $0.1 \%$ and $1000 \%$ were alternately loaded on the disk-shaped CEC-l-OSA hydrogels at a fixed frequency of $0.1 \mathrm{rad} / \mathrm{s}$ under $37^{\circ} \mathrm{C}$, and every strain were kept for $200 \mathrm{~s}$. As expected, the $G^{\prime}$ of the hydrogel could be repeatedly recovered to the original value after being broken down under large amplitude oscillatory. The results indicate that the CEC-l-OSA hydrogels with excellent self-healing performances can effectively repair the possibly damages due to mechanical interruption of the hydrogel structures, improve the functionalities and security level of cell transplantation with hydrogels as carriers.

Cytocompatibility, proliferation and differentiation of NSCs encapsulated in CEC-I-OSA hydrogel. To confirm the possibility of using the self-healing injectable hydrogels for nerve repair, the cytocompatibility, proliferation and differentiation of NSCs loaded inside the CEC-1-OSA hydrogels were examined and analyzed. The cytocompatibility of the model self-healing CEC-1-OSA hydrogels with $C_{\mathrm{c}}$ at $0.02 \mathrm{~g} / \mathrm{mL}$, was confirmed through Live/Dead test of NSCs loaded inside 3D hydrogels. The cell-loaded hydrogels can be facilely prepared by mixing NSCs suspension with CEC and OSA dissolved in DF-12 medium under physiological conditions (Fig. 5a). In contrast, the 2D culture of NSCs on the surface of commercial cell culture plates made of polystyrenes coated with polylysine and polyornithine/laminin were used as a $2 \mathrm{D}$ control (Fig. 5b). The cells stained in green are live cells, whereas cells stained in red are dead cells. The NSCs were uniformly dispersed into CEC-l-OSA hydrogels and exhibited c.a. $90 \%$ cell viability after cultivation for 1,3 and 5 days, which is similar to the control samples (Fig. 5c). These results demonstrate that the CEC-l-OSA hydrogel exhibits excellent cytocompatibility for NSCs.

To further evaluate the effects of injection through a needle on the cell viability, a piece of as-prepared NSC-loaded CEC-l-OSA hydrogel was push through a 21-gauge needle into a 24-well tissue culture plate (Fig. 6a). The extruded hydrogel fragments self-healed into one single piece hydrogel in each well after few minutes, and the cells loaded inside the self-healed hydrogels were continuously cultured. Although the extrusion pressure from the syringe may cause cellular damage, the cell viability of NSCs loaded inside the self-healed CEC-l-OSA hydrogel was $\sim 80 \%$ after cultivation for 1,3 and 5 days (Fig. $6 \mathrm{~b}$ ).

To analyze the proliferation of NSCs loaded inside the CEC-1-OSA hydrogels, BrdU/DAPI staining was used for evaluating cell proliferation in vitro. All the cell nuclei stained with DAPI are in blue, and the dividing cells immunostained with anti-BrdU antibody are in red. Thus, the cells with violet color are from the overlay of blue and red colors are the newly divided cells (Fig. 7a). The 2D cultivation of NSCs on commercial cell culture plates coated with polylysine and polyornithine/laminin was set as control (Fig. 7b). The results of BrdU/DAPI staining showed that the number of NSCs loaded inside the CEC-1-OSA hydrogels increased with culture time (1, 3 and 5 day) (Fig. 7a). When being cultivated for 1 day, the proliferation rate of the cells encapsulated in the CEC-1-OSA hydrogel was only $27.8 \pm 1.4 \%$, which was significantly lower than that of the $2 \mathrm{D}$ control group $(52.6 \pm 5.1 \%)$. After cultivation of 3 and 5 days, the proliferation rate of the cells encapsulated in the CEC-1-OSA hydrogel was increased to $72.6 \pm 2.6 \%$ and $89.0 \pm 4.0$, respectively, which was similar to that of the $2 \mathrm{D}$ control group ( $79.3 \pm 7.1 \%$ for 3 days and $87.4 \pm 2.0 \%$ for 5 days) (Fig. $7 \mathrm{c}$ ). It is considered that the NSCs may need appropriate time to adapt the $3 \mathrm{D}$ cultivation microenvironment on the initial day. After the adaptive stage, the NSCs can proliferate with culture time. These results illustrate that the CEC-1-OSA hydrogels are cytocompatible and favorable supporting scaffolds for the proliferation of NSCs in 3D microenvironments.

The CEC-1-OSA hydrogels also facilitate neuronal differentiation of NSCs. The neural stem cell marker, nestin, was demonstrated positively both for 3D hydrogel group and $2 \mathrm{D}$ control group on the first day (Supplementary Fig. S6). After replacing the differential medium and continuously cultured for 9 days, the 3D 

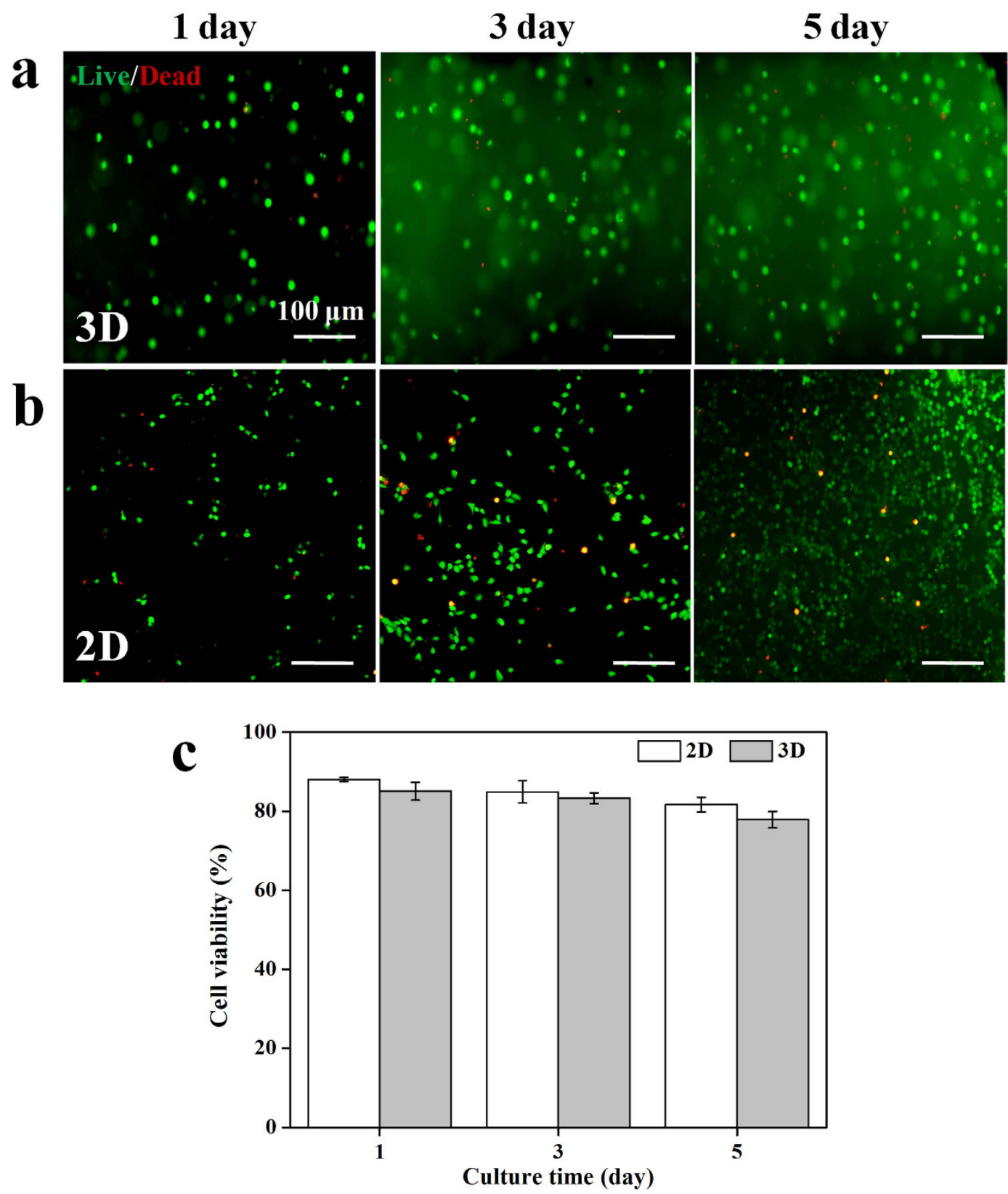

Figure 5. The cell viability of 3D and 2D cultures of NSCs. (a) Live/Dead staining of NSCs loaded inside the 3D CEC-1-OSA hydrogels $\left(C_{\mathrm{c}}=0.02 \mathrm{~g} / \mathrm{mL}\right)$ for 1,3 and 5 days. (b) Live/Dead staining of NSCs on the surface of tissue culture plastics for 1, 3 and 5 days. Live: green, dead: red. (c) The cell viability of NSCs under 2D and $3 \mathrm{D}$ conditions of different culture times of 1,3 and 5 days. There is no significant difference on the cell viability between $3 \mathrm{D}$ and $2 \mathrm{D}$ groups. Error bars represent standard deviations $(\mathrm{n}=3)$.

cultured cells inside the CEC-1-OSA hydrogels express much more neuronal marker, $\beta$-III tubulin, than the 2D control group (Fig. 8a,b). In contrast, the expression level of the glial marker GFAP in CEC-l-OSA hydrogels displayed the opposite results (Fig. 9a,b). The differentiated neuronal cells inside the CEC-1-OSA hydrogels were $38 \%$ higher than the 2D cultured group but the glial cells were $51 \%$ less than the control (Supplementary Fig. S7). This consequence may be not only attributed to the suitable stiffness of the CEC-l-OSA hydrogels $(\sim 500 \mathrm{~Pa})$, but also the chemical structure of the hydrogel. The dynamic cross-links of imine bonds containing dissociated amine groups in the CEC-1-OSA hydrogel networks can induce and promote the neuronal differentiation ${ }^{32-35}$. The differentiated neurons cultured on commercial cell culture plates extended long neurites (Fig. 8b). However, the morphology of neurons inside the hydrogel was still rounded, which should be a result of the limited growth of neurites in the restrictive 3D polymer networks of the hydrogel. We also injected the NSC-loaded CEC-l-OSA hydrogels in mice with focal cerebral ischemia model (Supplementary Fig. S8). The NSC-loaded hydrogels fully filled up the lesion site and the NSCs were observed uniformly distributed in the hydrogels. 

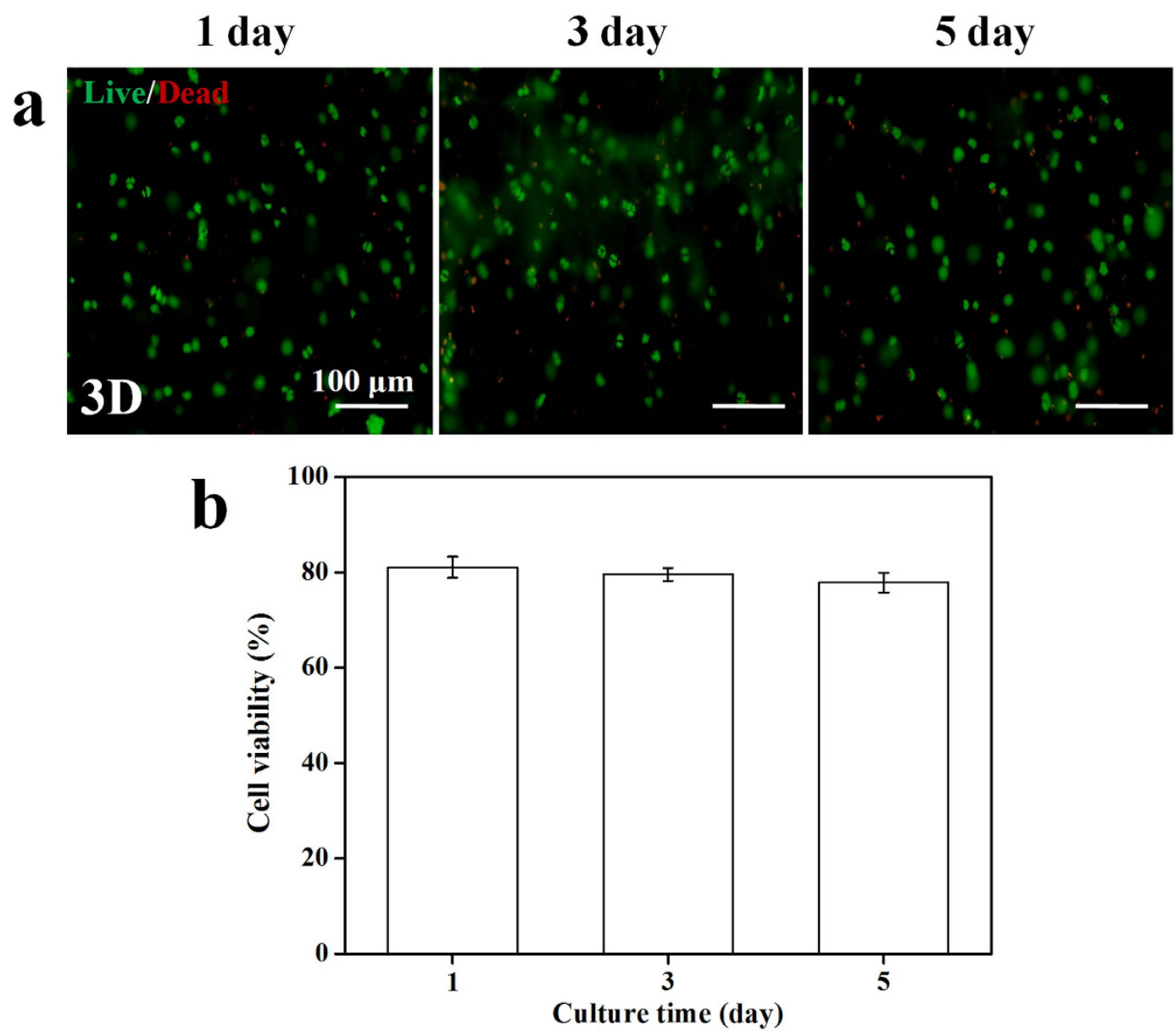

Figure 6. The cell viability of injected NSCs encapsulated in CEC-1-OSA hydrogels $\left(C_{\mathrm{c}}=0.02 \mathrm{~g} / \mathrm{mL}\right)$. (a) Live/Dead staining of the encapsulated NSCs after injection for 1, 3 and 5 day. Live: green, dead: red. (b) The cell viability versus different culture times. Error bars represent standard deviations $(\mathrm{n}=3)$.

\section{Conclusion}

In summary, we had developed a neurocompatible, injectable, and self-healing CEC-1-OSA hydrogel system, which was obtained by a Schiff reaction between polysaccharide CEC and OSA. The resultant dynamic imine bonds existed in the hydrogel networks impart the self-healing capability to the hydrogel under physiological conditions, which is confirmed by the injectable performance and self-healing capability based on rheological recovery tests and macroscopic observations. The biocompatible CEC-l-OSA hydrogels with the similar stiffness of nature brain tissues support the proliferation of NSCs loaded inside the 3D hydrogels. CEC-l-OSA hydrogels also favor neuronal differentiation of NSCs loaded inside the gels. The preparation of the CEC-l-OSA hydrogels is simple, scalable, low-cost and environment friendly. This investigation opens the door to polysaccharide-based self-healing hydrogels in the field of neural stem cell transplantation.

\section{Methods}

Materials. Sodium alginate ( $>350$ mpa.s), acrylic acid, and sodium periodate were purchased from Alfa Aesar. Chitosan (degree of deacetylation $86 \%, \mathrm{Mw}=200,000 \mathrm{Da}$ ) was ordered from Tokyo Kasei Kogyo Co., Ltd. All other chemicals were analytical grade and used without further purification.

Experimental procedures. Synthesis of $\mathrm{N}$-carboxyethyl chitosan (CEC). N-carboxyethyl chitosan was synthesized by our reported method ${ }^{19}$. Briefly, chitosan $(0.5 \mathrm{~g}, 3.1 \mathrm{mmol})$ was dissolved in $25 \mathrm{~mL}$ distilled water containing acrylic acid $(0.73 \mathrm{~mL}, 10.65 \mathrm{mmol})$, and the mixture was magnetically stirred under $50^{\circ} \mathrm{C}$ for 3 days. Then the $\mathrm{pH}$ of the solution was adjusted to $10-12$ by adding $1 \mathrm{~mol} / \mathrm{L} \mathrm{NaOH}$ solution dropwise. Thereafter, the solution was dialyzed (MWCO 8000) against distilled water for 3 days with repeated change of water, followed by freeze-dried to obtain the pure CEC powder. Typical yield of the products was $~ 75 \%$. The degree of substitution was around $38 \%$, which was determined according to the ${ }^{1} \mathrm{HNMR}$ spectra by comparing the peak area of the acetamide methyl protons $(\delta=1.94)$ in chitosan and the methylene protons $(\delta=2.83)$ of acrylic acid in CEC $\left({ }^{1} \mathrm{H}\right.$ NMR (400 MHz, $\left.\mathrm{D}_{2} \mathrm{O}, \delta\right): 1.94\left(\mathrm{~s}, 3 \mathrm{H}, \mathrm{COCH}_{3}\right), 2.83\left(\mathrm{~s}, 2 \mathrm{H}, \mathrm{CH}_{2} \mathrm{CO}_{2} \mathrm{Na}\right), 3.30 \sim 4.87$ (m, glucosamine)).

Synthesis of oxidized sodium alginate (OSA). The synthesis of OSA was based on the previous method with a slight modification ${ }^{19}$. Sodium alginate $(1.0 \mathrm{~g}, 5 \mathrm{mmol})$ was dissolved in $100 \mathrm{~mL}$ distilled water, then sodium 

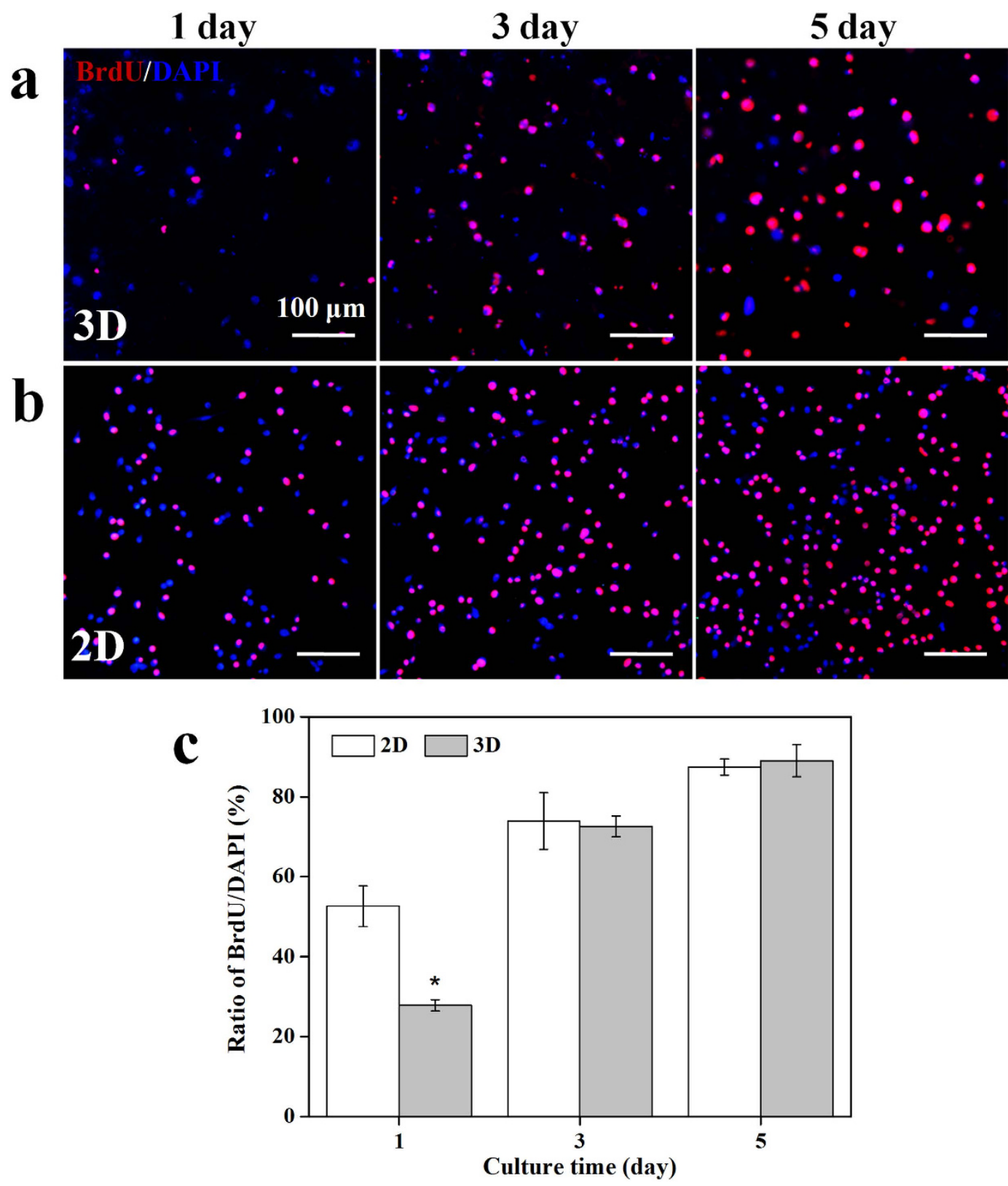

Figure 7. The proliferation of NSCs under 3D and 2D cultures. (a) The proliferation of NSCs loaded inside the CEC-l-OSA hydrogels $\left(C_{\mathrm{c}}=0.02 \mathrm{~g} / \mathrm{mL}\right)$ for 1,3 and 5 days, stained with BrdU/DAPI. (b) The proliferation of NSCs cultured on the surface of tissue culture plates for 1, 3 and 5 days, stained with BrdU/DAPI. All cell nuclei were stained with DAPI in blue, and the dividing cells were immunostained with anti-BrdU antibody in red. The cells with violet color derived from the overlay of blue and red color are the divided cells. (c) The percentage of proliferating cells, i.e., the ratio of BrdU positive cells to DAPI stained ones, at different culture times of 1 , 3 and 5 days. ${ }^{*}$ Symbol indicated the significant differences $(\mathrm{p}<0.05)$ between $2 \mathrm{D}$ and $3 \mathrm{D}$ cultures. Error bars represent standard deviations $(\mathrm{n}=3)$.

periodate $(0.54 \mathrm{~g}, 2.5 \mathrm{mmol})$ was added, and the solution was magnetically stirred in the dark at $25^{\circ} \mathrm{C}$ for $5 \mathrm{~h}$. The reaction was terminated by adding ethylene glycol $(1.5 \mathrm{~mL})$ and stirred for additional $1 \mathrm{~h}$. After the reaction, the mixture was dialyzed (MWCO 3000) against distilled water for 3 days with repeated change of water, followed by lyophilizing to obtain the products of OSA. Typical yield of the products was $\sim 80 \%$.

Determination of the degree of oxidation (DO). The DO was evaluated by the iodometry through determining the concentration of unconsumed periodate after the oxidized reaction. The $20 \mathrm{wt} \%$ potassium iodide solution $(2 \mathrm{~mL})$ was added to the reaction mixture $(5 \mathrm{~mL})$ after it was neutralized by adding $10 \mathrm{~mL}$ of $10 \mathrm{wt} \%$ sodium bicarbonate solution. The reaction was stirred in the dark at $25^{\circ} \mathrm{C}$ for $30 \mathrm{~min}$, and then the liberated iodine was titrated with standardized sodium thiosulphate solution $(0.01 \mathrm{~mol} / \mathrm{L})$ using starch $(1 \mathrm{wt} \%)$ as the indicator. The value of $\mathrm{DO}$ is $54 \%$, which is averaged from triplicate oxidation experiments. 


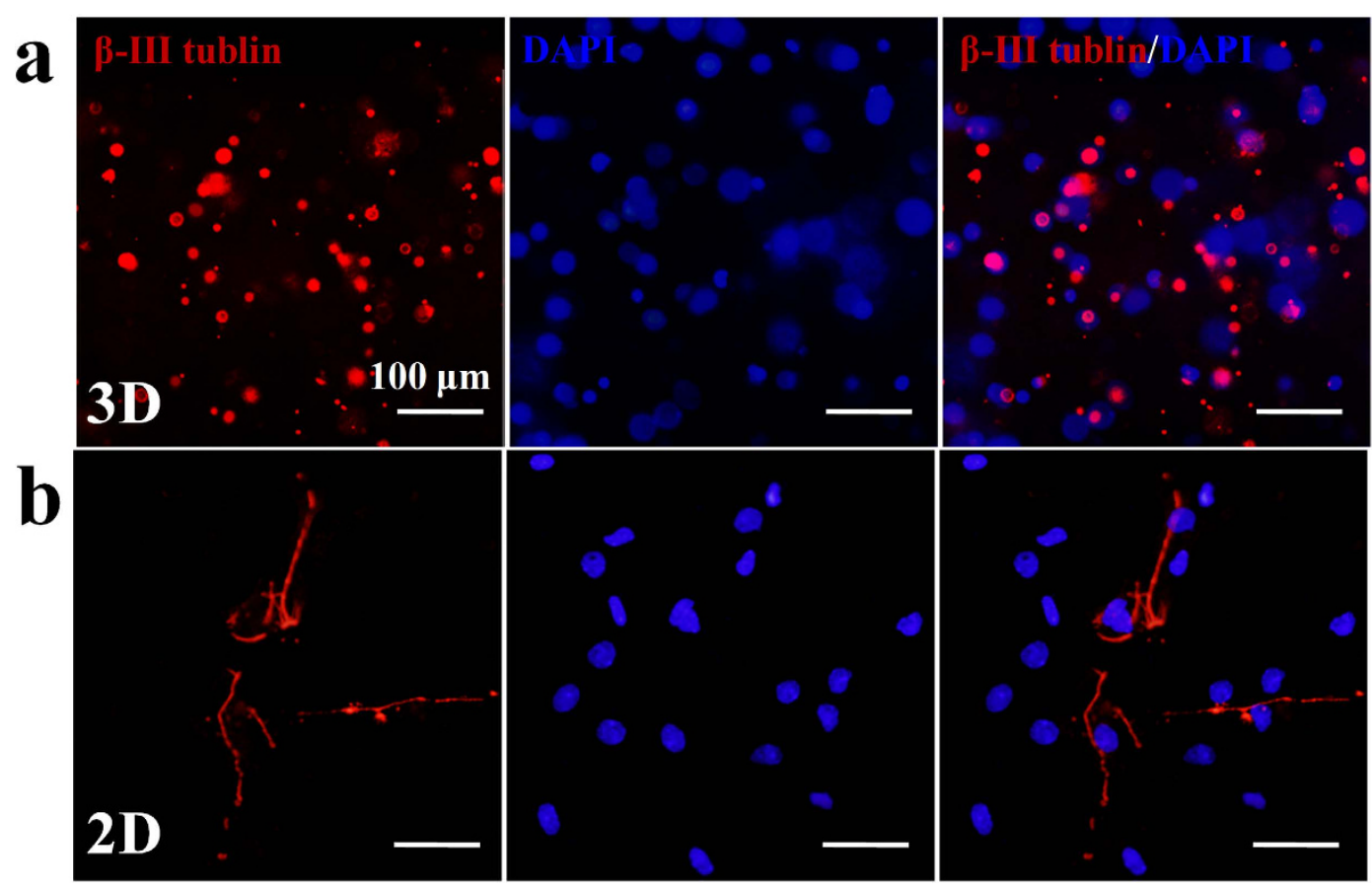

Figure 8. The neuronal differentiation of 3D and 2D cultured NSCs. (a) The expression of $\beta$-III tubulin marker of the NSCs loaded inside the CEC-1-OSA hydrogels $\left(C_{\mathrm{c}}=0.02 \mathrm{~g} / \mathrm{mL}\right)$ for 9 days. $(\mathbf{b})$ The expression of $\beta$-III tubulin marker of the NSCs cultured on 2D cell culture plates for 9 days. All the cell nuclei stained with DAPI are blue color, and the cells immunostained with $\beta$-III tubulin marker are red color.

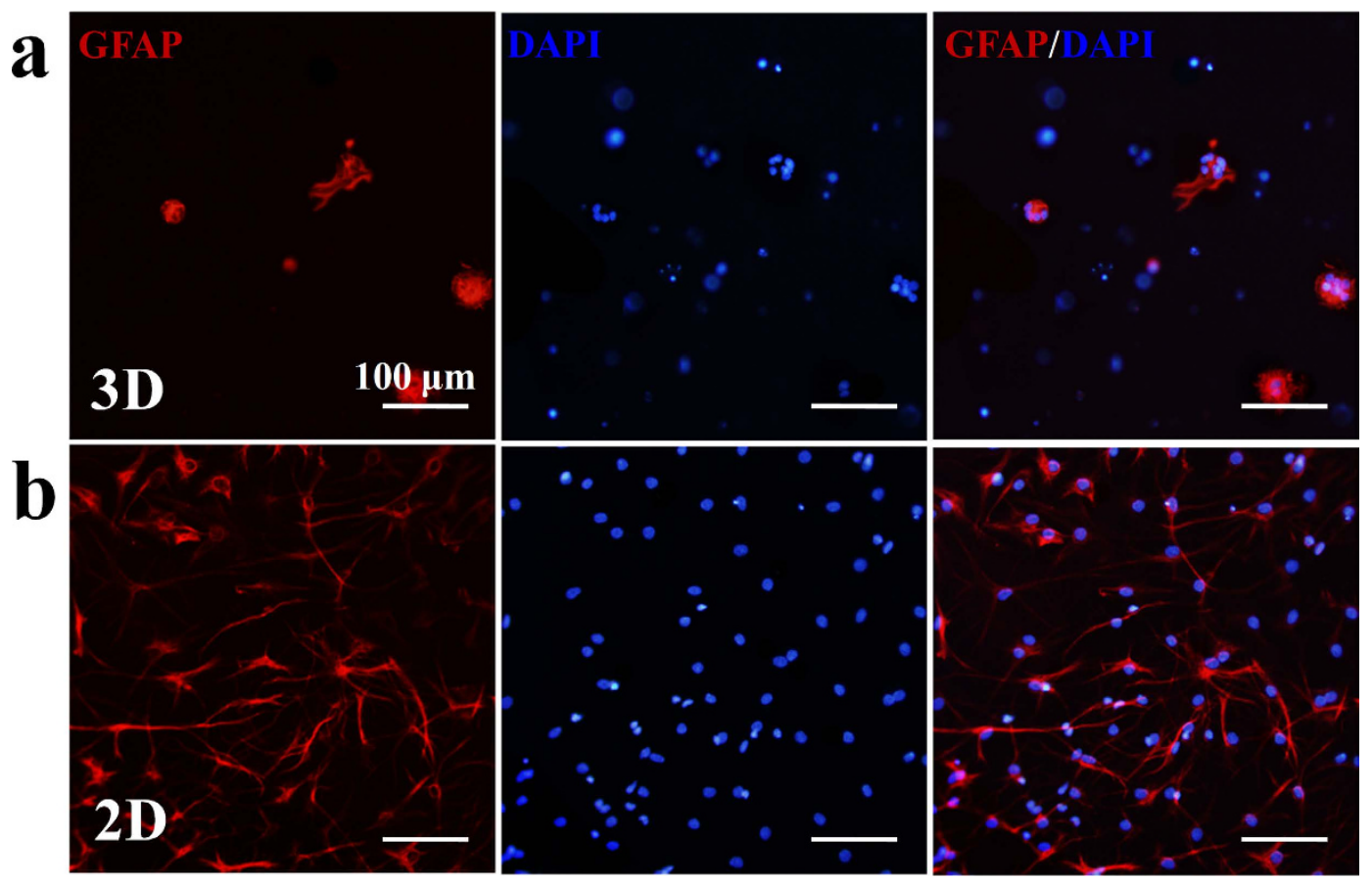

Figure 9. The glial differentiation of $3 \mathrm{D}$ and $2 \mathrm{D}$ cultured NSCs. (a) The expression of GFAP marker of the NSCs loaded inside CEC-1-OSA hydrogels $\left(C_{\mathrm{c}}=0.02 \mathrm{~g} / \mathrm{mL}\right)$ for 9 days. $(\mathbf{b})$ The expression of GFAP marker of the NSCs cultured on 2D cell culture plate surfaces for 9 days. All the cell nuclei were stained with DAPI in blue, and the cells were immunostained with GFAP marker in red.

Preparation of CEC-l-OSA hydrogel. The DMEM/F-12 (DF-12) medium solution of OSA $\left(C_{0}=0.1 \mathrm{~g} / \mathrm{mL}\right)$ were mixed with DF-12 solutions containing different concentrations of CEC $\left(C_{\mathrm{c}}=0.01,0.015,0.02,0.025\right.$ and $\left.0.03 \mathrm{~g} / \mathrm{mL}\right)$ 
at a fixed molar ratios $\left(\mathrm{M}-\mathrm{NH}_{2}: \mathrm{M}-\mathrm{CHO}=1\right)$ under $37^{\circ} \mathrm{C}$. The solution was mixed uniformly by vortex and eventually homogeneous hydrogels were obtained.

Measurement of gelation time of CEC-l-OSA hydrogels. Vial inversion method was applied to determine the gelation time. When no flow was observed and the different concentrations of CEC $\left(C_{c}=0.01,0.015,0.02,0.025\right.$ and $0.03 \mathrm{~g} / \mathrm{mL})$ with OSA $\left(C_{\mathrm{o}}=0.1 \mathrm{~g} / \mathrm{mL}\right)$ mixtures would be inversed at $37^{\circ} \mathrm{C}$, they were regarded as hydrogels. All the gelling times were measured in triplicate for each group.

Rheological measurements. 1) The storage moduli $\left(G^{\prime}\right)$ of CEC-1-OSA hydrogel discs ( $15 \mathrm{~mm}$ in diameter) with various $C_{\mathrm{c}}(0.01,0.015,0.02,0.025$ and $0.03 \mathrm{~g} / \mathrm{mL})$ and fixed $C_{\mathrm{o}}=0.1 \mathrm{~g} / \mathrm{mL}$ were tested with a rheometer equipped with parallel dentate anti-skid plates (both top and bottom plates are $15 \mathrm{~mm}$ in diameter) at $37^{\circ} \mathrm{C}$. Under a fixed strain of $0.1 \%$, the angular frequency was swept from $0.1 \mathrm{rad} \mathrm{s}^{-1}$ to $100 \mathrm{rad} \mathrm{s}^{-1}$. The $G^{\prime}$ of CEC-l-OSA hydrogel discs ( $15 \mathrm{~mm}$ in diameter) with various $C_{\mathrm{o}}(0.05,0.1$ and $0.2 \mathrm{~g} / \mathrm{mL})$ and fixed $C_{\mathrm{c}}=0.02 \mathrm{~g} / \mathrm{mL}$ were also tested by rheometer under same conditions (Supplementary Fig. S2). 2) The $G^{\prime}$ of the CEC-1-OSA hydrogels $\left(C_{\mathrm{c}}=0.02 \mathrm{~g} / \mathrm{mL}\right)$ with gelation time of $5 \mathrm{~min}$ and $24 \mathrm{~h}$ as well as the self-healing hydrogel with healing time of $5 \mathrm{~min}$ after injection, were tested at $37^{\circ} \mathrm{C}$ under a fixed strain of $0.1 \%$ and angular frequency of $10 \mathrm{rad} \mathrm{s}^{-1}$. 3) The alternate step strain sweep of CEC-l-OSA hydrogel discs $\left(15 \mathrm{~mm}\right.$ in diameter) with $C_{\mathrm{c}}=0.02 \mathrm{~g} / \mathrm{mL}$ was measured at a fixed angular frequency $\left(10 \mathrm{rad} \mathrm{s}^{-1}\right)$ at $37^{\circ} \mathrm{C}$. Amplitude oscillatory strains were switched from small strain $(\gamma=0.1 \%)$ to subsequent large strain $(\gamma=1000 \%)$ with 200 s for every strain interval.

Measurement of the degradation rates of CEC-l-OSA hydrogels. The degradation of CEC-1-OSA hydrogels $\left(C_{\mathrm{c}}=0.01,0.015,0.02,0.025\right.$ and $\left.0.03 \mathrm{~g} / \mathrm{mL}\right)$ was determined through weighing the samples at different time points. Hydrogels $\left(W_{0}\right)$ were immersed in microtubes with $500 \mu \mathrm{L}$ of DF- 12 medium at $37^{\circ} \mathrm{C}$. The medium was removed from each sample at pre-determined time points. The weight of each samples $\left(W_{t}\right)$ were measured. Fresh medium were added into the microtubes after each weighing. The degradation ratio was then calculated by $W_{\mathrm{t}} / W_{0}$.

Self-healing test of the CEC-l-OSA hydrogels. Disc-shaped CEC-1-OSA hydrogels $\left(C_{\mathrm{c}}=0.02 \mathrm{~g} / \mathrm{mL}\right)$ were put into syringes and extruded through 21 -gauge needles into number molds of " 2 ", " 0 ", " 1 ", " 5 " and cultured for 5 min at $37^{\circ} \mathrm{C}$ without any external intervention. The newly formed hydrogel numbers " 2 ", " 0 ", " 1 ", " 5 " were taken out from the mold and immersed in PBS ( $\mathrm{pH}$ 7.4). Their stability was observed by gently shaking and inverting the vials.

Neural stem cells (NSCs) isolation and culture. 1) NSCs were isolated from cerebral cortex of fetal rats at E14. The cells were expanded as neurospheres in serum-free DF-12 medium supplemented with $100 \mathrm{mg} / \mathrm{mL}$ penicillin-streptomycin, $20 \mathrm{ng} / \mathrm{mL}$ epidermal growth factor (EGF), $10 \mathrm{ng} / \mathrm{mL}$ basic fibroblast growth factor (bFGF), B27 supplement and N2 supplement in incubator for 3-5 days. After trypsin incubation, cells were subcultured on poly-lysine and poly-ornithine/laminin-coated commercial tissue culture plates. 2) As for differentiation study, NSCs dissociated from neurospheres were seeded on culture plates as above and cultured in differentiation medium consisting of DF-12 medium, penicillin-streptomycin, B27 supplement, N2 supplement and fetal bovine serum (FBS) for 9 days. The medium was exchanged every other day.

NSC loading into CEC-l-OSA hydrogels. For the tests of cell viability and proliferation, NSCs were loaded inside CEC-l-OSA hydrogels in a density of $1 \times 10^{6}$ cells $/ \mathrm{mL}$. For the differentiation study, the density was $1 \times 10^{5}$ cells/ $\mathrm{mL}$. Briefly, CEC $\left(C_{\mathrm{c}}=0.02 \mathrm{~g} / \mathrm{mL}\right)$ and OSA $\left(C_{\mathrm{o}}=0.1 \mathrm{~g} / \mathrm{mL}\right)$ were dissolved in DF- 12 medium, respectively. After trypsin digestion and centrifugation of NSCs, NSCs were re-suspended in $900 \mu \mathrm{L}$ CEC DF-12 solution followed by mixing with $100 \mu \mathrm{L}$ OSA DF-12 solution. The mixture was rapidly plated in 24 well-plates within $30 \mathrm{~s}$ to form gel samples in each well. In order to collect these gel samples, we pre-positioned one cover slip in each well. The control group was the culture of NSCs on commercial cell culture plates. The samples were placed in a $\mathrm{CO}_{2}$ incubator at $37^{\circ} \mathrm{C}$ and $50 \%$ of the medium was changed every 3 days. For the proliferation study, bromodeoxyuridine (BrdU) was added to each well. These NSC-loaded CEC-l-OSA hydrogels were collected and processed by the following evaluations. 1) Cell viability was determined by a live/dead assay after culturing for 1, 3 and 5 days. 2) Cell proliferation test was assessed by immunofluorescent staining after culturing for 1, 3 and 5 days. 3) Cell differentiation was examined by immunofluorescent staining after culturing for 9 days.

Cell viability test. To investigate the viability of NSCs, a live/dead assay was performed. Briefly, the NSCs loaded CEC-l-OSA hydrogels were rinsed with $0.01 \mathrm{~mol} / \mathrm{L}$ PBS. In dark condition, 300-500 $\mu \mathrm{L}$ of stain solution (prepared by $4 \mathrm{mmol} / \mathrm{L}$ ethidium homodimer- 1 and $2 \mathrm{mmol} / \mathrm{L}$ calcein $\mathrm{AM}$ in $0.01 \mathrm{~mol} / \mathrm{L} \mathrm{PBS}$ ) was added into each well and the samples were incubated for $3 \mathrm{~min}$ at room temperature. The stain solution was discarded and the samples were washed with 1X PBS twice. Then they were fixed with $4 \%$ paraformaldehyde for $30 \mathrm{~min}$ and washed with 1 X PBS again. 50\% glycerol was added on the samples as mounting medium before fluorescence microscope observation and analysis.

Immunostaining. Immunostaining was performed to identify NSCs, investigate proliferation, and detect differentiation of cells seeded inside the CEC-1-OSA hydrogels. 1) For the proliferation detection, cells were firstly fixed with $4 \%$ paraformaldehyde for $20 \mathrm{~min}$, then incubated with $2 \mathrm{~mol} / \mathrm{L} \mathrm{HCl}$ solution (in order to open the double-stranded DNA of cells) for $1 \mathrm{~h}$, and neutralized with $0.1 \mathrm{~mol} / \mathrm{L}$ boric acid solution. After that, the cells were permeabilized with $0.3 \%$ Triton X-100 for $30 \mathrm{~min}$, and blocked in $2 \%$ goat serum for $1 \mathrm{~h}$ at room temperature. Then they were incubated with primary antibody, mouse monoclonal anti-BrdU (1:200 dilution) for $2 \mathrm{~h}$ at 
room temperature and at $4{ }^{\circ} \mathrm{C}$ overnight. Thereafter, the primary antibody solution was discarded and samples were washed with $1 \mathrm{X}$ PBS for three times. The secondary antibody, anti-mouse Cy3 secondary antibody (1:2000 dilution), was added and incubated for $2 \mathrm{~h}$ at room temperature. DAPI (1:1000 dilution) solution was used to stain nuclei for $5 \mathrm{~min}$ at room temperature. 2) For identify NSCs, cells were fixed with $4 \%$ paraformaldehyde for $20 \mathrm{~min}$, permeabilized with $0.3 \%$ Triton X-100 for $30 \mathrm{~min}$, and blocked in $2 \%$ goat serum for $1 \mathrm{~h}$ in room temperature. Thereafter, samples were incubated with primary antibody, mouse monoclonal anti-nestin (1:200 dilution), for $2 \mathrm{~h}$ at room temperature and at $4{ }^{\circ} \mathrm{C}$ overnight. Then the primary antibody solution was discarded and the samples were washed with 1X PBS for three times. The secondary antibody, anti-mouse FITC secondary antibody (1:200 dilution), was added and incubated for $2 \mathrm{~h}$ at room temperature. DAPI (1:1000 dilution) solution was used to stain nuclei for $5 \mathrm{~min}$ at room temperature. 3) For differentiation evaluation, cells were fixed with $4 \%$ paraformaldehyde for $20 \mathrm{~min}$, permeabilized with $0.3 \%$ Triton X-100 for $30 \mathrm{~min}$, and blocked in $2 \%$ goat serum for $1 \mathrm{~h}$ at room temperature. Thereafter, the samples were incubated with primary mouse monoclonal anti- $\beta$-tublin III (1:200 dilution), and rabbit monoclonal anti-GFAP (1:200 dilution) for $2 \mathrm{~h}$ at room temperature and at $4{ }^{\circ} \mathrm{C}$ overnight. Then the primary antibody solution was discarded and cells were washed with $1 \mathrm{X}$ PBS for three times. The following secondary antibodies including anti-mouse Cy3 (1:2000 dilution) and anti-goat TRITC (1:200 dilution) were then subsequently added, respectively, and incubated for $2 \mathrm{~h}$ at room temperature. DAPI (1:1000 dilution) solution was used to stain nuclei for $5 \mathrm{~min}$ at room temperature. Samples were examined under fluorescence microscope and quantitatively analyzed.

Cells and animal study. The rats were purchased from the Experiment Animal Center, Medical School of Xi'an Jiaotong University (Xian, China). The animals were housed and handled in strict accordance with the Guidelines of the Institutional and National Committees of Animal Use and Protection. The protocols were approved by the Committee on the Ethics of Animal Experiments of Xi'an Jiaotong University (Certificate No. 22-9601018). All efforts were made to minimize animals' suffering and the numbers of animals used. All methods were performed in accordance with the relevant guidelines and regulations by including a statement in the Methods section to this effect.

\section{References}

1. Gage, F. H. Mammalian neural stem cells. Science 287, 1433-1438 (2000).

2. Temple, S. The development of neural stem cells. Nature 414, 112-117 (2011).

3. Kelly, S. et al. Transplanted human fetal neural stem cells survive, migrate, and differentiate in ischemic rat cerebral cortex. Proc. Natl. Acad. Sci. USA 101, 11839-11844 (2004).

4. Tresco, P. A., Biran, R. \& Noble, M. D. Cellular transplants as sources for therapeutic agents. Adv. Drug Deliv. Rev. 42, 3-27 (2000).

5. Chen, F. M., Wu, L. A., Zhang, M., Zhang, R. \& Sun, H. H. Homing of endogenous stem/progenitor cells for in situ tissue regeneration: Promises, strategies, and translational perspectives. Biomaterials 32, 3189-3209 (2011).

6. Park, K. M. \& Gerecht, S. Hypoxia-inducible hydrogels. Nat. Commun. 5, 4075-4086 (2014).

7. Yuk, H., Zhang, T., Parada, G. A., Liu, X. \& Zhao, X. Skin-inspired hydrogel-elastomer hybrids with robust interfaces and functional microstructures. Nat. Commun. 7, 12028-12038 (2016).

8. Chen, Y. M., Liu, Z. Q., Feng, Z. H., Xu, F. \& Liu, J. K. Adhesive protein-free synthetic hydrogels for retinal pigment epithelium cell culture with low ROS level. Biomed. Mater. Res. A 102, 2258-2267 (2013).

9. Liu, Z. Q. et al. Dextran-based hydrogel formed by thiol-Michael addition reaction for 3D cell encapsulation. Colloid Surface B 128, 140-148 (2015)

10. Shen, Y. I. et al. Engineered human vascularized constructs accelerate diabetic wound healing. Biomaterials 102, 117-119 (2016).

11. Gyenes, T., Torma, V., Gyarmati, B. \& Zrínyi, M. Synthesis and swelling properties of novel pH-sensitive poly(aspartic acid) gels. Acta Biomater. 4, 733-744 (2008).

12. Cheng, T. Y., Chen, M. H., Chang, W. H., Huang, M. Y. \& Wang T. W. Neural stem cells encapsulated in a functionalized selfassembling peptide hydrogel for brain tissue engineering. Biomaterials 34, 2005-2016 (2013).

13. Lim, T. C., Toh, W. S., Wang, L. S., Kurisawa, M. \& Spector, M. The effect of injectable gelatin-hydroxyphenyl propionic acid hydrogel matrices on the proliferation, migration, differentiation and oxidative stress resistance of adult neural stem cells. Biomaterials 33, 3446-3455 (2012).

14. Alessandri, K. et al. A 3D printed microfluidic device for production of functionalized hydrogel microcapsules for culture and differentiation of human Neuronal Stem Cells (hNSC). Lab Chip 16, 1593-1604 (2016).

15. Wei, Z. et al. Self-healing gels based on constitutional dynamic chemistry and their potential applications. Chem. Soc. Rev. 43, 8114-8131 (2014).

16. Wei, Z. et al. Dextran-based self-healing hydrogels formed by reversible Diels-Alder reaction under physiological conditions. Macromol. Rapid Commun. 34, 1464-1470 (2013).

17. Wool, R. P. Self-healing materials: a review. Soft Matter 4, 400-418 (2008).

18. Li, S. C., Han, P. \& Xu, H. P. Self-healing polymeric materials. Prog. Chem. 24, 1346-1352 (2012).

19. Wei, Z. et al. Novel biocompatible polysaccharide-based self-healing hydrogel. Adv. Funct. Mater. 25, 1352-1359 (2015).

20. Ding, F. et al. A dynamic and self-crosslinked polysaccharide hydrogel with autonomous self-healing ability. Soft Matter 11, 3971-3976 (2015).

21. Yang, B. et al. Facilely prepared inexpensive and biocompatible self-healing hydrogel: a new injectable cell therapy carrier. Polym. Chem. 3, 3235-3238 (2012)

22. Appel, E. A., Barrio, J. D., Loh, X. J. \& Scherman, O. A. Supramolecular polymeric hydrogels. Chem. Soc. Rev. 41, 6195-6214 (2012).

23. Guvendiren, M., Lu, H. D. \& Burdick, J. A. Shear-thinning hydrogels for biomedical applications. Soft Mater 8, 260-272 (2012).

24. Haines-Butterick, L. et al. Controlling hydrogelation kinetics by peptide design for three-dimensional encapsulation and injectable delivery of cells. Proc. Natl. Acad. Sci. USA 104, 7791-7796 (2007).

25. Chiu, Y. L. et al. $\mathrm{pH}$-triggered injectable hydrogels prepared from aqueous $N$-palmitoyl chitosan: In vitro characteristics and in vivo biocompatibility. Biomaterials 30, 4877-4888 (2009).

26. Kretlow, J. D., Klouda, L. \& Mikos, A. G. Injectable matrices and scaffolds for drug delivery in tissue engineering. Adv. Drug Delivery Rev. 59, 263-273 (2007).

27. Yu, L. \& Ding, J. Injectable hydrogels as unique biomedical materials. Chem. Soc. Rev. 37, 1473-1481 (2008).

28. Temenoff, J. S. \& Mikos, A. G. Injectable biodegradable materials for orthopedic tissue engineering. Biomaterials 21, 2405-2412 (2000).

29. Hou, S., Wang, X., Park, S., Jin, X. \& Ma, P. X. Rapid self-integrating, injectable hydrogel for tissue complex regeneration. Adv. Healthcare Mater. 4, 1491-1495 (2015). 
30. Liu, S. et al. Injectable and self-healing carbohydrate-based hydrogel for cell. ACS Appl. Mater. Interfaces 7, 13029-13037 (2015).

31. Tharanathan, R. N. \& Kittur, F. S. Chitin-the undisputed biomolecule of great potential. Crit. Rev. Food Sci. Nutr. 43, 61-87 (2003).

32. Ren, Y. J. et al. In vitro behavior of neural stem cells in response to different chemical functional groups. Biomaterials 30, 1036-1044 (2009).

33. Callahan, L. A. S., Ma, Y., Stafford, C. M. \& Becker, M. L. Concentration dependent neural differentiation and neurite extension of mouse ESC on primary amine-derivatized surfaces. Biomater. Sci. 1, 537-544 (2013).

34. Wang, Y. et al. Chitosan degradation products promote nerve regeneration by stimulating schwann cell proliferation via miR-27a/ FOXO1 axis. Mol. Neurobiol. 53, 28-39 (2016).

35. Jiang, M., Zhuge, X., Yang, Y., Gu, X. \& Ding, F. The promotion of peripheral nerve regeneration by chitooligosaccharides in the rat nerve crush injury model. Neurosci. Lett. 454, 239-243 (2009).

36. Vanderhooft, J. L., Mann, B. K. \& Prestwich, G. D. Synthesis and characterization of novel thiol-reactive poly (ethylene glycol) crosslinkers for extracellular-matrix-mimetic biomaterials. Biomacromolecules 8, 2883-2889 (2007).

37. Lin, S., Sangai, N., Razafiarison, T., Zhang, C. \& Varghese, S. Influence of physical properties of biomaterials on cellular behavior. Pharm. Res. 28, 1422-1430 (2011)

38. Kothapalli, C. R. \& Kamm, R. D. 3D matrix microenvironment for targeted differentiation of embryonic stem cells into neural and glial lineages. Biomaterials 34, 5995-6007 (2013).

39. Leipzig, N. D. \& Shoichet, M. S. The effect of substrate stiffness on adult neural stem cell behavior. Biomaterials 30, 6867-6878 (2009)

\section{Acknowledgements}

This research was supported by the National Natural Science Foundation of China (No. 11674263, 51173144 and 31271023), the project was supported by the Major Research plan of the National Natural Science Foundation of China (No. 91323104), International Science \& Technology Cooperation Program was supported by Ministry of Science and Technology of China and Shaanxi Province (2013KW14-02), the Research Fund for the Doctoral Program of Higher Education of China, the Scientific Research Foundation for the Returned Overseas Chinese Scholars, State Education Ministry, the Fundamental Research Funds for the Central Universities, the Program for the Key Science and Technology Innovative Team of Shaanxi Province (No. 2013KCT-05), Collaborative Innovation Center of Suzhou Nano Science and Technology, Suzhou Research Institute (SYG201522, BY2013036).

\section{Author Contributions}

Z.W. and J.Z. designed and performed research, analyzed data. Z.W. and Y.M.C. analyzed the results and wrote the paper. B.Z. and Q.Z. analyzed the results and revised the paper. All authors reviewed the manuscript.

\section{Additional Information}

Supplementary information accompanies this paper at http://www.nature.com/srep

Competing financial interests: The authors declare no competing financial interests.

How to cite this article: Wei, Z. et al. Self-healing polysaccharide-based hydrogels as injectable carriers for neural stem cells. Sci. Rep. 6, 37841; doi: 10.1038/srep37841 (2016).

Publisher's note: Springer Nature remains neutral with regard to jurisdictional claims in published maps and institutional affiliations.

(c) (i) This work is licensed under a Creative Commons Attribution 4.0 International License. The images or other third party material in this article are included in the article's Creative Commons license, unless indicated otherwise in the credit line; if the material is not included under the Creative Commons license, users will need to obtain permission from the license holder to reproduce the material. To view a copy of this license, visit http://creativecommons.org/licenses/by/4.0/

(C) The Author(s) 2016 